\title{
SLC26A4 gene copy number variations in Chinese patients with non-syndromic enlarged vestibular aqueduct
}

\author{
Jiandong Zhao ${ }^{1,2}$, Yongyi Yuan ${ }^{1,2}$, Jing Chen ${ }^{1}$, Shasha Huang ${ }^{1}$, Guojian Wang ${ }^{1,2}$, Dongyi Han ${ }^{1 *}$ and Pu Dai ${ }^{1,2^{*}}$
}

\begin{abstract}
Background: Many patients with enlarged vestibular aqueduct (EVA) have either only one allelic mutant of the SLC26A4 gene or lack any detectable mutation. In this study, multiplex ligation-dependent probe amplification (MLPA) was used to screen for copy number variations (CNVs) of SLC26A4 and to reveal the pathogenic mechanisms of non-syndromic EVA (NSEVA).

Methods: Between January 2003 and March 2010, 923 Chinese patients (481 males, 442 females) with NSEVA were recruited. Among these, 68 patients (7.4\%) were found to carry only one mutant allele of SLC26A4 and 39 patients (4.2\%) lacked any detectable mutation in SLC26A4; these 107 patients without double mutant alleles were assigned to the patient group. Possible copy number variations in SLC26A4 were detected by SALSA MLPA.
\end{abstract}

Results: Using GeneMapper, no significant difference was observed between the groups, as compared with the standard probe provided in the assay. The results of the capillary electrophoresis showed no significant difference between the patients and controls.

Conclusion: Our results suggest that CNVs and the exon deletion in SLC26A4 are not important factors in NSEVA. However, it would be premature to conclude that CNVs have no role in EVA. Genome-wide studies to explore CNVs within non-coding regions of the SLC26A4 gene and neighboring regions are warranted, to elucidate their roles in NSEVA etiology.

Keywords: Enlarged vestibular aqueduct (EVA), MLPA, SLC26A4, Copy number variations (CNVs), Mutation

\section{Introduction}

Copy number variations (CNVs) or copy number polymorphisms are complex gains or losses of several to hundreds of kilobases of DNA as a result of deletions, insertions, duplications, and complex multi-site variants. CNVs are found throughout the human genome [1]. CNVs are much more frequent than chromosomal aberrations. They also encompass more nucleotide content per genome than single-nucleotide polymorphisms (SNPs) $[2,3]$. Therefore, CNVs may be more significantly correlated with phenotypic variations, and they may play vital roles in the evolution and development of species [4].

\footnotetext{
*Correspondence: hdy301@263.net; daipu301@vip.sina.com

'Department of Otolaryngology, PLA General Hospital, Beijing, People's Republic of China

${ }^{2}$ Department of Otolaryngology, Hainan Branch of PLA General Hospital, Sanya, People's Republic of China
}

Multiplex ligation-dependent probe amplification (MLPA) was used to screen for CNVs of the SLC26A4 gene in the present study. MLPA is a novel semi-quantitative method that was first developed by Schouten and colleagues in 2002 [5]. It allows the simultaneous processing of multiple sequences (up to 45) with various copy numbers. MLPA involves the hybridization of probes and target sequences, followed by ligation and PCR amplification. The amplified products are visualized by capillary electrophoresis, and the peak area and peak height of the amplified products are analyzed to reveal the relative copy number of the target sequence.

$S L C 26 A 4$, which is also known as the Pendred syndrome $(P D S)$ gene, is located on human chromosome $7 \mathrm{q} 31$. It contains $57175 \mathrm{bp}$ and its mRNA is $4930 \mathrm{bp}$ in length, encompassing 21 exons and containing an open reading frame (ORF) of $2343 \mathrm{bp}$. The ORF starts from 
exon 2 and continuously traverses the other 20 exons. SLC26A4 encodes Pendrin, which has a molecular mass of $86 \mathrm{kDa}$ and contains 780 amino acids [6]. Pendrin is a transmembrane protein that is mainly composed of hydrophobic amino acids. It is a member of the anion transporter family and contains an intracellular $\mathrm{N}$-terminus, a C-terminus, and 12 transmembrane domains. Pendrin is expressed in the cells of the thyroid gland, kidney, and inner ear. Pendrin functions in the transportation of anions, including $\mathrm{SO}_{4}^{-}, \mathrm{HCO}_{3}^{-}, \mathrm{CHOO}^{-}$, $\mathrm{C}_{2} \mathrm{O}_{2}^{2-}, \mathrm{OH}^{-}, \mathrm{Cl}^{-}, \mathrm{I}^{-}$, and $\mathrm{C}_{6} \mathrm{H}_{12} \mathrm{O}_{6}$. Therefore, it plays a crucial role in maintaining the balance of ions [7]. In the inner ear, Pendrin is primarily expressed in the non-sensory structures, such as the external sulcus epithelial cells of the Corti organ and the endolymphatic duct and sac epithelial cells, and is involved in endolymphic fluid homeostasis. Pendrin, as a transporter of $\mathrm{Cl}^{-} / \mathrm{HCO}_{3}^{-}$, regulates the ion balance of the endolymphic fluid [8]. Mutations in the SLC26A4 gene may lead to autosomal-recessive deafness (DFNB4) and Pendred syndrome (non-syndromic enlarged vestibular aqueduct [NSEVA], inner ear malformation, sensorineural hearing loss, and goiter) [9].

SLC26A4 gene mutations have the characteristic of allelic heterogeneity, i.e., deaf patients from different races may have a spectrum of mutations. In Northern Europe, T416P and IVS8 $+1 \mathrm{G}>\mathrm{A}$ are considered to be the most common mutations [10], while in France, the mutations are extremely diverse [11]. Among Asians, H723R is the most frequently observed mutation in Japanese and Korean populations [12,13], while 919-2A $>\mathrm{G}$ is the most common mutation in Chinese subjects $[14,15]$. One study has indicated that SLC26A4 biallelic mutations (homozygote or complex heterozygote) cause NSEVA, while a person with a monoallelic mutation can only be a carrier [16]. However, many EVA patients have only one or no mutant allele of the SLC26A4 gene. One explanation for the pathogenesis of these EVA cases is that the mutation is located within the promoter region or intronic cryptic splicing; these types of mutations are not readily detected by current screening approaches [17]. Another study has suggested the involvement of environmental factors or mutations in other genes [18]. However, these speculations have not been confirmed by relevant studies.

In the current study, we recruited patients with NSEVA who had no detectable SLC26A4 mutation or only carried one mutant allele of SLC26A4. All the cases were diagnosed by the Molecular Diagnostics Center for Deafness, Institute of Otorhinolaryngology, PLA General Hospital. To date, no study of CNVs in SLC26A4 has been conducted. In the present study, we used MLPA to screen patients for SLC26A4 CNVs and to reveal the pathogenic mechanisms of NSEVA.

\section{Materials and Methods \\ Recruitment of subjects \\ Patients with NSEVA}

Between January 2003 and March 2010, 923 patients (481 males, 442 females) who were diagnosed as having NSEVA by computer tomography (CT) or MRI were recruited at the Molecular Diagnostics Center for Deafness, Institute of Otorhinolaryngology, PLA General Hospital. Among these patients, 262 (28.4\%) carried SLC26A4 homozygous mutations and 554 (60\%) had complex heterozygous mutations. For the current study, 68 patients $(7.4 \%)$ with one allele mutant and 39 patients (4.2\%) without any detectable mutation were recruited. The average age of the 68 patients (32 males and 36 females) who carried one allele mutation in SLC26A4 was 7.86 years (range, 3 months to 33 years; $S D=7.56$ ). The average age of the 39 patients (23 males and 16 females) who lacked SLC26A4 mutation was 9.65 years (range, $1-34$ years; $\mathrm{SD}=8.95$ ). All the NSEVA cases were diagnosed by high-resolution CT or MRI. Vestibular aqueduct enlargement was diagnosed if the vestibular aqueduct was $>1.5 \mathrm{~mm}$ in the middle portion of the descending limb in the axial plane, based on a CT scan of the temporal bone [19]. The MRI diagnostic criteria for vestibular enlargement included: diameter of the intra-osseous endolymphatic duct at its midpoint being $>1.5 \mathrm{~mm}$, an enlarged intra-osseous endolymphatic sac; and the T2-weighted signal intensity of the endolymphatic duct being designated as "high" [20].

\section{"Healthy" controls}

Controls were recruited from persons with a normal hearing examination and no family history of hereditary hearing loss. Genomic DNA samples were collected from these subjects as negative (wild-type) controls. In accordance with the MLPA experimental design criterion that the ratio of patients to controls should be $7: 1,16$ controls (8 males and 8 females) were selected for the current study. The average age of the control subjects was 9.23 years (range, $2-36$ years; $\mathrm{SD}=8.76$ ). No statistically significant difference in age was observed between the patients and controls.

All patients and controls signed informed consent forms, and this study obtained the approval of the People's Liberation Army General Hospital Ethics Committee.

\section{DNA extraction, quantification, and quality assessment}

DNA samples were extracted from the peripheral blood leukocytes using standard procedures. The extracted DNA was stored at $-20^{\circ} \mathrm{C}$ until use. The DNA concentration and absorbance were measured in a spectrophotometer (Beckman Coulter DU800) at $280 \mathrm{~nm}$ and $260 \mathrm{~nm}$. The ratio of absorbance readings at $260 \mathrm{~nm}$ and $280 \mathrm{~nm}$ (A260/A280) provides an estimate of the purity 
of the nucleic acid. All the extracted DNA samples had A260/A280 ratios of between 1.5 and 2.0.

\section{MLPA analysis}

CNVs in the SLC26A4 gene were detected using the SALSA MLPA KIT P280-A1 Pendred-SLC26A4 kit (MRC Holland, Amsterdam, The Netherlands). MLPA permits relative quantification of changes in the copy number of a specific genomic region. The P280 PendredSLC26A4 probe mix contains probes for each of the 21 exons of the SLC26A4 gene. In addition, two mutationspecific probes were designed for the IVS $8+1 \mathrm{G}>\mathrm{A}$ donor splice mutation and the T416P amino acid substitution. MLPA was performed in accordance with the manufacturer's instructions (MRC Holland). Briefly, DNA samples were diluted with TE to $5 \mu \mathrm{l}$ and heated at $98^{\circ} \mathrm{C}$ for $5 \mathrm{~min}$. After cooling the samples to $25^{\circ} \mathrm{C}, 1.5 \mu \mathrm{l}$ of probe mix (containing $1 \mathrm{fmol}$ of each probe) and $1.5 \mu \mathrm{l}$ of MLPA hybridization buffer were added, and the solution was denatured at $95^{\circ} \mathrm{C}$ for $1 \mathrm{~min}$ and hybridized at $60^{\circ} \mathrm{C}$ for $16 \mathrm{~h}$. Hybridized probes were ligated at $54^{\circ} \mathrm{C}$ for 15 min after the addition of $32 \mu \mathrm{l}$ of the ligation mixture. Following heat inactivation at $98^{\circ} \mathrm{C}$ for $5 \mathrm{~min}, 10 \mu \mathrm{l}$ of the ligation reaction were mixed with $30 \mu \mathrm{l}$ of PCR buffer, heated to $60^{\circ} \mathrm{C}$, mixed with $10 \mu \mathrm{l}$ of PCR mixture and amplified by PCR $\left(35\right.$ cycles of $30 \mathrm{~s}$ at $95^{\circ} \mathrm{C}$, $30 \mathrm{~s}$ at $60^{\circ} \mathrm{C}$, and $1 \mathrm{~min}$ at $72^{\circ} \mathrm{C}$, followed 1 cycle of $20 \mathrm{~min}$ at $72^{\circ} \mathrm{C}$ ). The following PCR primers were used: forward, 5'-GGGTTCCCTAAGGGTTGGA-3'; and reverse, 5'-GTGCCAGCAAGATCCAATCTAGA-3'. The amplified products were analyzed in the ABI 3130 Avant capillary electrophoresis system. The genes and sequences recognized by the probes used in the present study can be found at www.mrc-holland.com.

\section{Results}

\section{Characteristics of the study subjects}

The NSEVA group included 107 patients who either carry one allele mutation in the $S L C 26 A 4$ gene or lack a detectable mutation in SLC26A4. All cases were diagnosed and confirmed as NSEVA by CT and MRI scan (Figure 1). In total, 16 "healthy" controls were selected from subjects with a normal hearing examination and no family history of hereditary hearing loss. No significant differences were found for age or gender between the patients and controls $(p<0.05)$ (Table 1$)$.

\section{Comparisons of the experimental data for the patients and controls}

Experimental data were generated using the GeneMapper Software (ver. 3.7), and included six aspects: dye/sample peak; sample file name; size; height; area; and data-points. The preliminary data analyses did not reveal significant differences for capillary electrophoresis

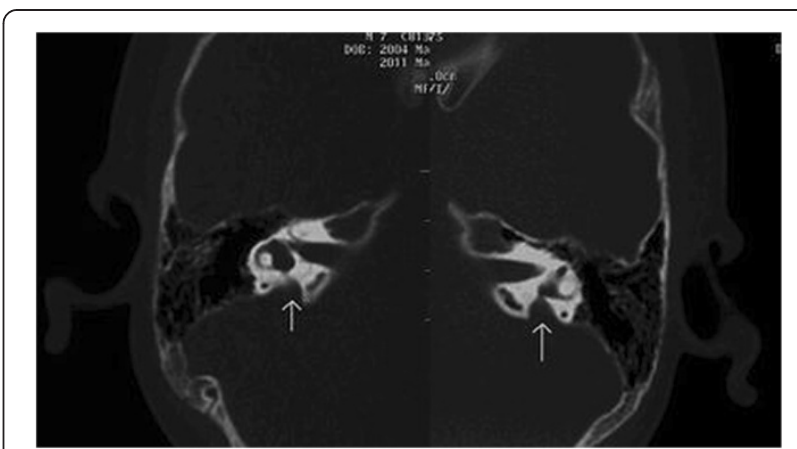

Figure 1 Image of the bilateral enlarged vestibular aqueducts.

profile or for sample peak, size, height, area, and datapoints. Some of the results are shown in Figure 2.

All the data were analyzed further using the Coffalyser MLPA Software, which generates a relative ratio from a comparison of the patients and controls. This ratio is regarded as 'normal' when it is within the range of $0.5-1.5$. A ratio of $<0.5$ suggests a fragment deletion, while a ratio $>1.5$ indicates duplication. All the results for the 107 patients showed a normal ratio, which suggests that these patients lacked CNVs (deletions or duplications).

\section{Discussion}

The difference in genome sequences between individuals is generally estimated to be less than $0.1 \%$, and the differences are mainly manifested as SNPs. However, with the completion of the Human Genome Project, it is becoming clear that the genomic differences among healthy individuals are $>0.1 \%$, and include many variations [21]. The individual genomic variations may be quantitatively described as copy number gains (insertions and duplications), losses (deletions), transpositions (translocations and rearrangements), and inversions. Compared with SNPs, the frequency of $\mathrm{CNVs}$ is low, although the implicated sequences are much longer than SNPs, indicating that CNVs may have a greater impact on human diseases and health [22]. To date, more than 6,000 CNVs (http://projects.tcag.ca/variation) have been identified in the human genome. There have been reports of significant correlations between CNVs and deafness. For example, Knijnenburg et al. found a homozygous deletion on 15q15.3 in a CNV using comparative genomic hybridization (CGH) and MLPA [23]. This deletion of approximately $90 \mathrm{~kb}$ contains four genes, including the STRC gene linked to the DFNB16 locus. The latter is

Table 1 Characteristics of the NSEVA cases and controls

\begin{tabular}{llll}
\hline & $\mathbf{N}$ & $\begin{array}{l}\text { Age in } \\
\text { years (SD) }\end{array}$ & $\begin{array}{l}\text { Gender } \\
\text { ratio (M/F) }\end{array}$ \\
\hline NSEVA cases & 107 & $8.73(8.27)$ & $1.1: 1$ \\
\hline Controls & 16 & $9.23(8.76)$ & $1: 1$ \\
\hline
\end{tabular}




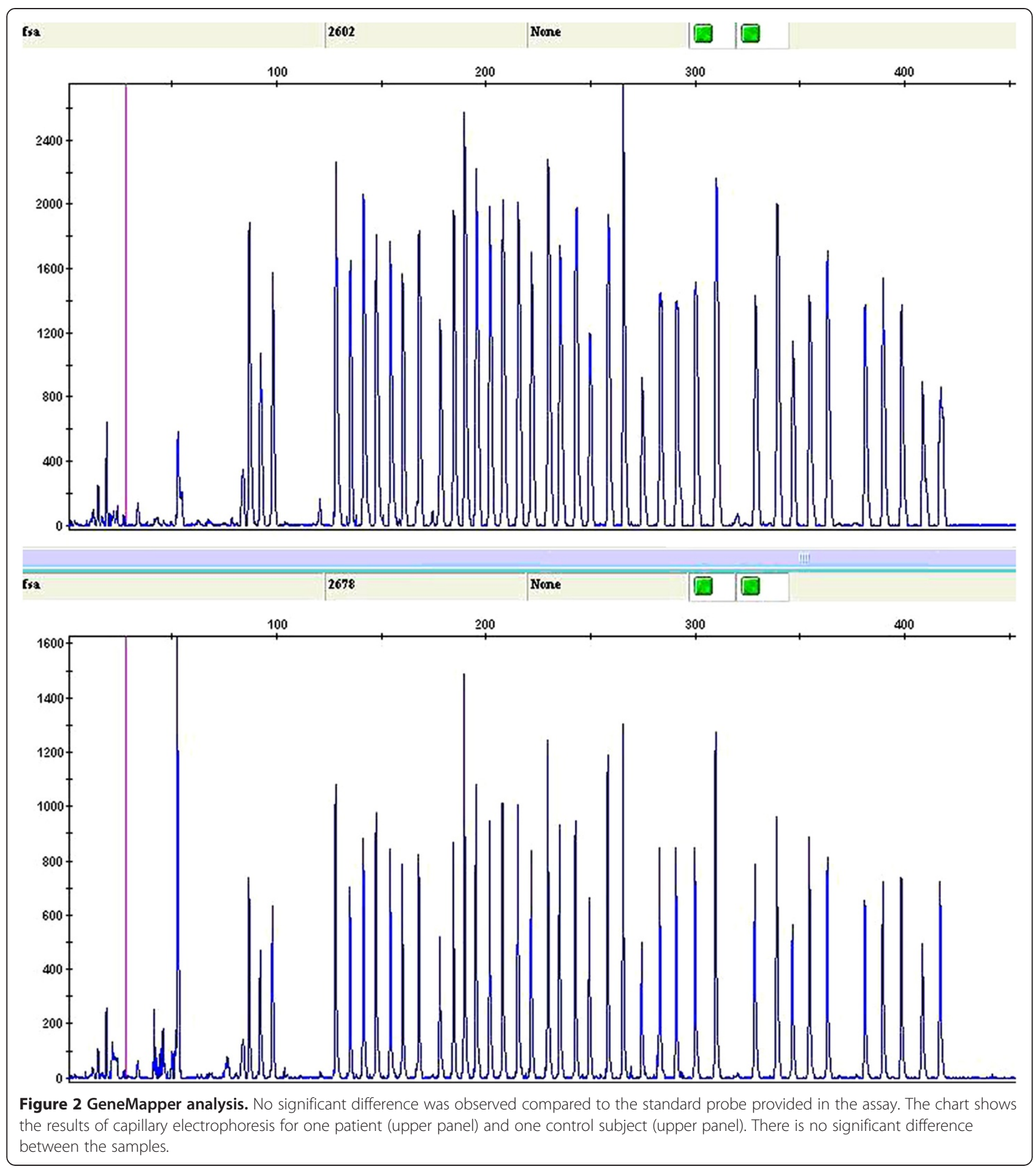

known to be involved in autosomal recessive deafness [23]. Another study has reported that complex rearrangements of the 7q21.3 region are related to bilateral split-foot malformation and hearing loss [24]. MLPA, which is a semiquantitative method with good sensitivity based on a simple quantitative PCR reaction, allows the simultaneous hybridization and ligation of probes. When this is followed by PCR amplification and capillary electrophoresis analysis, MLPA can detect multiple CNVs within DNA sequences $[25,26]$. This method has been widely used to study inherited diseases. In the current study, we applied MLPA to screen for CNVs in a deafness-related gene, SLC26A4.

The SLC26A4 gene was first localized and cloned by Everett and colleagues from patients with Pendred 
syndrome [27]. The SLC26A4 gene contains 21 exons and an ORF of $2343 \mathrm{bp}$. A clear demarcation was found between each intron and exon. The multiple exons observed in the gene indicate that it encodes a protein with a complex structure and function. The ORF of $S L C 26 A 4$ starts at exon 2 and continuously traverses the other 20 exons. The exons are $55 \mathrm{bp}$ to $231 \mathrm{bp}$ in length and encode the Pendrin protein, which contains 780 amino acids [6]. Pendrin is composed of hydrophobic amino acids and belongs to the anion transporter families. Its functions are associated with the transportation of anions, such as $\mathrm{I}^{-}, \mathrm{Cl}^{-}$, and $\mathrm{HCO}_{3}^{-}$[28].

Pendrin is primarily expressed in the external sulcus epithelial cells of the Corti organ and the endolymphatic duct and sac in the inner ear. These non-sensory structures are correlated with the metabolism of endolymphic fluid. Pendrin, as a transporter of $\mathrm{Cl}^{-}$, may regulate the ion balance of the endolymphic fluid. It is well known that the homeostasis of the endolymphic fluid plays a pivotal role in the development of the inner ear. If homeostasis is disrupted, the osseous structures of the cochlea and vestibular aqueduct may be affected. Therefore, mutations in SLC26A4 may lead to enlargement of the vestibular aqueduct [29].

Mutations in the SLC26A4 gene are considered to be extremely heterogeneous [30]. The distributions of mutant SLC26A4 alleles differ significantly among various ethnic populations [14,31,32]. Many different types of variations in SLC26A4 have been found, including missense, nonsense, splice site, and frameshift mutations. However, there has been no report as to whether CNVs exist in the SLC26A4 gene, which is the main topic of the current study.

We applied MLPA to screen for CNVs in the 21 exons of the SLC26A4 gene in 107 patients with NSEVA who carry one or no mutant allele of $S L C 26 A 4$. However, the results did not reveal any copy number gain or loss in the SLC26A4 genes of these patients. There were several possible explanations for this observation. First, it is possible that no CNVs are present in the exons of SLC26A4, which would mean that CNVs are not the cause of the enlarged vestibular aqueduct. Second, CNVs may be present in SLC26A4 but are located within the introns or lie upstream or downstream of the regulatory regions, i. e., not within the ORF. The MLPA assay is unable to detect these CNVs. Third, CNVs may exist in the genes adjacent to SLC26A4 or in genes with regulatory functions for SLC26A4. These CNVs may alter the expression patterns or the functions of target genes, thereby indirectly affecting the SLC26A4 gene, and ultimately causing enlargement of the vestibular aqueduct. Based on these results and interpretations, it is premature to conclude that $\mathrm{CNV}$ has no causative role in enlarged vestibular aqueduct. Genome-wide studies to explore CNVs within the non-coding regions of SLC26A4 are warranted, to elucidate their roles in the etiology of NSEVA.

\section{Conclusion}

Our results suggest that CNVs and the exon deletion in SLC26A4 are not important factors in NSEVA. However, it would be premature to conclude that CNVs have no role in EVA. Genome-wide studies to explore CNVs within non-coding regions of the SLC26A4 gene and neighboring regions are warranted in order to elucidate their roles in NSEVA etiology.

\section{Competing interest}

The authors declare that they have no competing interests. This document has been checked by at least two professional editors, both native speakers of English. For a certificate, please see: http://www.textcheck.com/certificate/ $1 \mathrm{rPIDr}$

\section{Acknowledgments}

This work was supported by grants from the Chinese National Nature Science Foundation (30572015, 30728030, 31071109), State 863 High Technology R\&D Key Project of China (SQ2010AA0221634001), and MOST (2012BAI09B02) to Dr. Pu Dai, by grants from the Chinese National Nature Science Foundation (30801285) and Beijing Nova Programme (2009B34) to Dr. Yongyi Yuan, and by grants from the Chinese National Nature Science Foundation (81000415) and Beijing Nova Programme (2010B081) to

Dr. Guojian Wang.

\section{Authors' contributions}

JD Zhao carried out the molecular genetic studies, participated in the sequence alignment and drafted the manuscript. YY Yuan carried out the immunoassays. J Chen participated in the sequence alignment. SS Huang and GJ Wang participated in the design of the study and performed the statistical analysis. DY Han and P Dai conceived of the study, and participated in its design and coordination and helped to draft the manuscript. All authors read and approved the final manuscript.

Received: 3 February 2012 Accepted: 2 May 2012

Published: 2 May 2012

\section{References}

1. lafrate AJ, Feuk L, Rivera MN, Listewnik ML, Donahoe PK, Qi Y, Scherer SW, Lee C: Detection of large-scale variation in the human genome. Nat Genet 2004, 36(9):949-951.

2. Redon $R$, Ishikawa S, Fitch KR, Feuk L, Perry GH, Andrews TD, Fiegler $H$, Shapero MH, Carson AR, Chen W, Cho EK, Dallaire S, Freeman JL, González JR, Gratacòs M, Huang J, Kalaitzopoulos D, Komura D, MacDonald JR, Marshall CR, Mei R, Montgomery L, Nishimura K, Okamura K, Shen F, Somerville MJ, Tchinda J, Valsesia A, Woodwark C, Yang F, et al: Global variation in copy number in the human genome. Nature 2006, 23(7118):444-454

3. Hinds DA, Kloek AP, Jen M, Chen X, Frazer KA: Common deletions and SNPs are in link age disequilibrium in the human genome. Nat Genet 2006, 38(1):82-85.

4. Beckmann JS, Estivill X, Antonarakis SE: Copy number variants an d genetic traits:closer to the resolution of phenotypic to genotypic variability. Nat Rev Genet 2007, 8(8):639-664.

5. Schouten JP, McElgunn CJ, Waaijer R, Zwijnenburg D, Diepvens F, Pals G. Relative quantification of 40 nucleic acid sequences by multiplex ligation-dependent probe amplification. Nucleic Acids Res 2002, 30(12):e57.

6. Kopp P: Pendred's syndrome: identification of the genetic defect a century after its recognition. Thyroid 1999, 9(1):65-69.

7. Dossena S, Rodighiero S, Vezzoli V, Nofziger C, Salvioni E, Boccazzi M, Grabmayer E, Bottà G, Meyer G, Fugazzola L, Beck-Peccoz P, Paulmichl M: Functional characterization of wild-type and mutated pendrin (SLC26A4), the anion transporter involved in Pendred syndrome. J Mol Endocrinol 2009, 43(3):93-103. 
8. Lang F, Vallon V, Knipper M, Wangemann P: Functional significance of channels and transporters expressed in the inner ear and kidney. Am J Physiol Cell Physiol 2007, 293(4):C1187-C1208.

9. Dossena S, Vezzoli V, Cerutti N, Bazzini C, Tosco M, Sironi C, Rodighiero S, Meyer G, Fascio U, Fürst J, Ritter M, Fugazzola L, Persani L, Zorowka P, Storelli C, Beck-Peccoz P, Bottà G, Paulmichl M: Functional characterization of wild-type and a mutated form of SLC26A4 identified in a patient with Pendred syndrome. Cell Physiol Biochem 2006, 17(5-6):245-256.

10. Campbell C, Cucci RA, Prasad S, Green GE, Edeal JB, Galer CE, Karniski LP, Sheffield VC, Smith RJ: Pendred syndrome, DFNB4, and PDS/SLC26A4 identification of eight novel mutations and possible genotypephenotype correlations. Hum Mutat 2001, 17(5):403-411.

11. Blons H, Feldmann D, Duval V, Messaz O, Denoyelle F, Loundon N, SergoutAllaoui A, Houang M, Duriez F, Lacombe D, Delobel B, Leman J, Catros H, Journel H, Drouin-Garraud V, Obstoy MF, Toutain A, Oden S, Toublanc JE, Couderc R, Petit C, Garabédian EN, Marlin S: Screening of SLC26A4 (PDS) gene in Pendred's syndrome: a large spectrum of mutations in France and phenotypic heterogeneity. Clin Genet 2004, 66(4):333-340.

12. Tsukamoto K, Suzuki H, Harada D, Namba A, Abe S, Usami S: Distribution and frequencies of PDS (SLC26A4) mutations in Pendred syndrome and nonsyndromic hearing loss associated with enlarged vestibular aqueduct: a unique spectrum of mutations in Japanese. Eur I Hum Genet 2003, 11(12):916-922.

13. Cho MA, Jeong SJ, Eom SM, Park HY, Lee YJ, Park SE, Park SY, Rhee Y, Kang ES, Ahn CW, Cha BS, Lee EJ, Kim KR, Lee HC, Lim SK: The H723R mutation in the PDS/SLC26A4 gene is associated with typical Pendred syndrome in Korean patients. Endocrine 2006, 30(2):237-243.

14. YaL Z, QiuJ W, Lan L, Yuan H, Guan J, XuB CH, Zong L, ZaiS Q: Investigation of SLC26A4 mutations in families associated with non-syndromic enlarged vestibular aqueduct. Chinese Journal of Otology 2006, 4(4):322-328.

15. Yong YY: Study on Molecular Epidemiology and Pathogenesis of Severe to Profound Hearing Loss in China: Doctoral dissertation of general hospital of PLA; 2007.

16. Pryor SP, Madeo AC, Reynolds JC, Sarlis NJ, Arnos KS, Nance WE, Yang Y, Zalewski CK, Brewer CC, Butman JA, Griffith AJ: SLC26A4/PDS genotypephenotype correlation in hearing loss with enlargement of the vestibular aqueduct (EVA): evidence that Pendred syndrome and non-syndromic EVA aredistinct clinical and genetic entities. J Med Genet 2005, 42:159-165.

17. Yang T, Vidarsson H, Rodrigo-Blomqvist S, Rosengren SS, Enerback S, Smith RJ: Transcriptional control of SLC26A4 is involved in Pendred syndrome and nonsyndromic enlargement of vestibular aqueduct (DFNB4). Am J Hum Genet 2007, 80(6):1055-1063.

18. Bogazzi F, Russo D, Raggi F, Ultimieri F, Berrettini S, Forli F, Grasso L, Ceccarelli C, Mariotti S, Pinchera A, Bartalena L, Martino E: Mutations in the SLC26A4 (pendrin) gene in patients with sensorineural deafness and enlarged vestibular aqueduct. J Endocrinol Invest 2004, 27(5):430-435.

19. Goldfeld M, Glaser B, Nassir E, Gomori JM, Hazani E, Bishara N: CT of the ear in Pendred syndrome. Radiology 2005, 235(2):537-540.

20. Oh SH, Choi BY, Son KR, Lee KJ, Chang SO, Kim CS: Can magnetic resonance imaging provide clues to the inner ear functional status of enlarged vestibular aqueduct subjects with PDS mutation? Otol Neurotol 2008, 29(5):593-600

21. Scherer SW, Lee C, Birney E, Altshuler DM, Eichler EE, Carter NP, Hurles ME, Feuk $L$ : Challenges and standards in integrating surveys of structural variation. Nat Genet 2007, 39(7Suppl):S7-S15.

22. The Human Genome Structural Variation Working Group: Completing the map of human genetic variation. A plan to identify and integrate normal structural variation into the human genome sequence. Nature 2007, 447(10):161-165.

23. Knijnenburg J, Oberstein SA, Frei K, Lucas T, Gijsbers AC, Ruivenkamp CA, Tanke HJ, Szuhai K: A homozygous deletion of a normal variation locus in a patient with hearing loss from non-consanguineous parents. J Med Genet 2009, 46(6):412-417.

24. Saitsu H, Kurosawa K, Kawara H, Eguchi M, Mizuguchi T, Harada N, Kaname T, Kano H, Miyake N, Toda T, Matsumoto N: Characterization of the complex 7q21.3 rearrangement in a patient with bilateral split-foot malformation and hearing loss. Am J Med Genet A 2009, 149A(6):1224-1230.

25. den Dunnen JT, White SJ: MLPA and MAPH: sensitive detection of deletions and duplications. Curr Protoc Hum Genet 2006, Chapter 7: Unit 7.14 .
26. Tepeli E, Muslumanoglu MH, Uludag A, Buyukpinarbasili N, Ozdemir M, Oznur M, Aslan H, Artan S: Detection of deletions and/or amplifications of genes related with lung cancer by multiplex ligation-dependent probe amplification (MLPA) technique. Cancer Biol Ther 2009, 8(22):2160-2165.

27. Everett LA, Glaser B, Beck JC, Idol JR, Buchs A, Heyman M, Adawi F, Hazani E, Nassir E, Baxevanis AD, Sheffield VC, Green ED: Pendred syndrome is caused by mutations in a putative sulphate transporter gene(PDS). Nat Genet 1997, 17(4):411-422.

28. Scott DA, Karniski LP: Human pendrin expressed in Xenopus laevis oocytes mediates chloride/formate exchange. Am J Physiol Cell Physiol 2000, 278(1):C207-C211.

29. Wu CC, Lu YC, Chen PJ, Yeh PL, Su YN, Hwu WL, Hsu CJ: Phenotypic analyses and mutation screening of the SLC26A4 and FOXI1 genes in 101 Taiwanese families with bilateral nonsyndromic enlarged vestibular aqueduct (DFNB4) or Pendred syndrome. Audiol Neurootol 2010, 15(1):57-66.

30. Azaiez H, Yang T, Prasad S, Sorensen JL, Nishimura CJ, Kimberling WJ, Smith RJ: Genotype-phenotype correlations for SLC26A4-related deafness. Hum Genet 2007, 122(5):451-457.

31. Tekin M, Akçayöz D, Comak E, Boğoçlu G, Duman T, Fitoz S, Ihan I, Akar N: Screening the SLC26A4 gene in probands with deafness and goiter (Pendred syndrome) ascertained from a large group of students of the schools for the deaf in Turkey. Clin Genet 2003, 64(4):371-374.

32. Gillam MP, Bartolone L, Kopp P, Benvenga S: Molecular analysis of the PDS gene in a nonconsanguineous Sicilian family with Pendred's syndrome. Thyroid 2005, 15(7):734-741.

doi:10.1186/1479-5876-10-82

Cite this article as: Zhao et al:: SLC26A4 gene copy number variations in Chinese patients with non-syndromic enlarged vestibular aqueduct. Journal of Translational Medicine 2012 10:82.

\section{Submit your next manuscript to BioMed Central and take full advantage of:}

- Convenient online submission

- Thorough peer review

- No space constraints or color figure charges

- Immediate publication on acceptance

- Inclusion in PubMed, CAS, Scopus and Google Scholar

- Research which is freely available for redistribution 